\title{
РАЗРАБОТКА МАТЕМАТИЧЕСКОЙ МОДЕЛИ ВЕКТОРНОГО УПРАВЛЕНИЯ АСИНХРОННОГО КОРОТКОЗАМКНУТОГО ДВИГАТЕЛЯ В СРЕДЕ МАТЛАБ
}

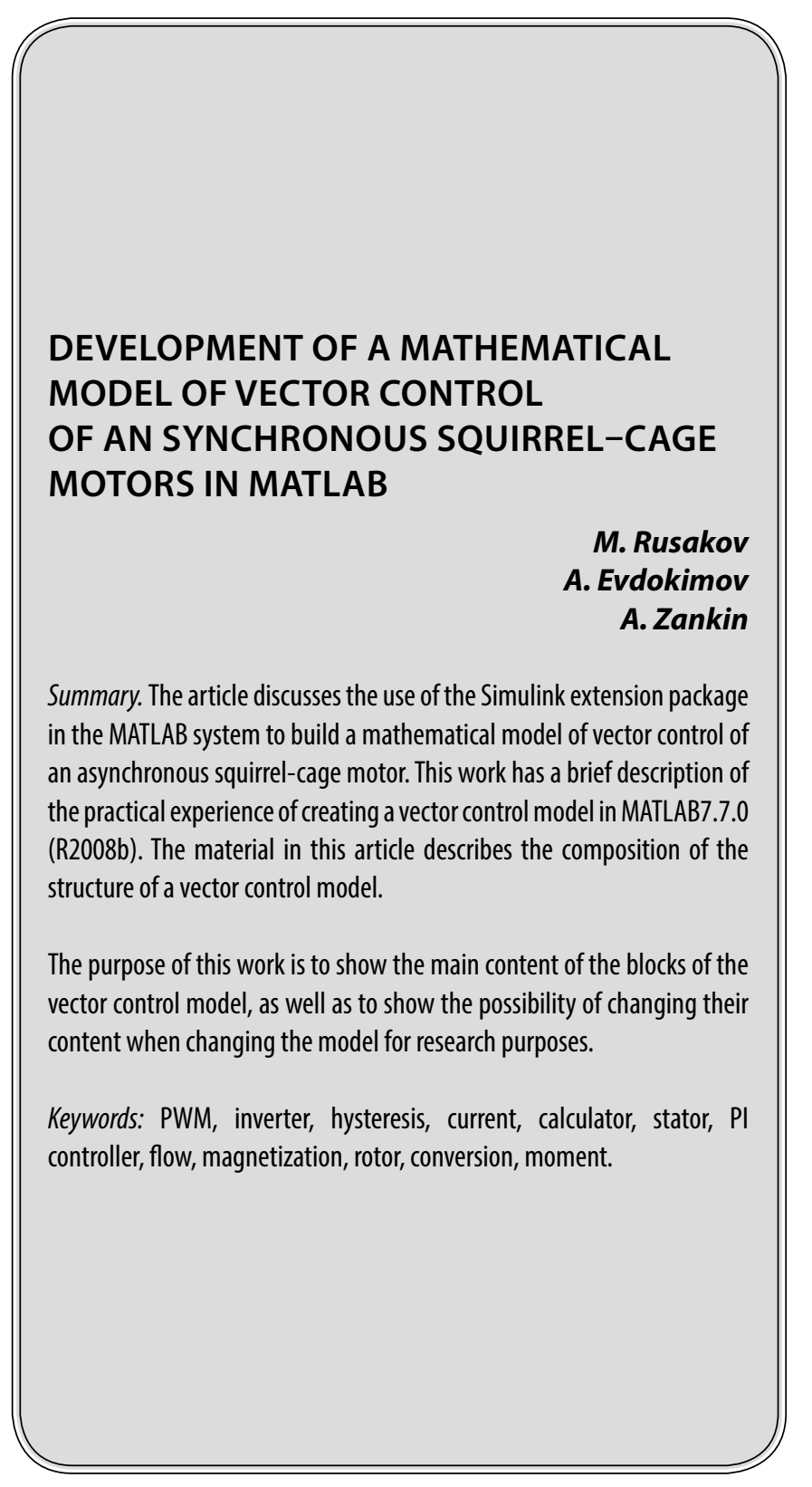

$\mathbf{H}$ а сегодняшний день при разработке многих устройств немаловажное значение имеет математическое моделирования. Математическое моделирование позволяет наглядно оценить технические характеристики устройства при разных условиях работы и технических параметров самого устройства. В данной статье продемонстрировано создание матема-
Русаков Максим Геннадьевич Аспирант, ФГБОУ ВО «Мордовский ГУ им. Н.П. Огарёва» e10e00@mail.ru

Евдокимов Александр Сергеевич Аспирант, ФГБОУ ВО «Мордовский ГУ им. Н.П. Огарёва» evd15@list.ru

Занкин Александр Иванович Аспирант, ФГБОУ ВО «Мордовский ГУ им. Н.П. Огарёва» zankin_ai@mail.ru

Аннотация. В статье рассматривается применение пакета расширения Simulink в системе MATLAB, для построения математической модели векторного управления асинхронным короткозамкнутым двигателем. Данная работа имеет краткое описание практического опыта создания модели векторного управления в MATLAB7.7.0 (R2008b). Материал данной статьи описывает состав структуры модели векторного управления.

Цель данной работы показать основное содержание блоков модели векторного управления, а также показать возможности изменения их содержания при изменении модели в исследовательских целях.

Ключевые слова: ШИМ, инвертор, гистерезис, ток, вычислитель, статор, ПИ-регулятор, поток, намагничивание, ротор, преобразование, момент. тической модели векторного управления асинхронным двигателем с короткозамкнутым ротором. Управление потоком ротора асинхронного короткозамкнутого двигателя имеет немаловажное значение, поскольку это позволяет использовать асинхронный короткозамкнутый двигатель подобно тяговому двигателю постоянного тока. Подобное управление также носить название 


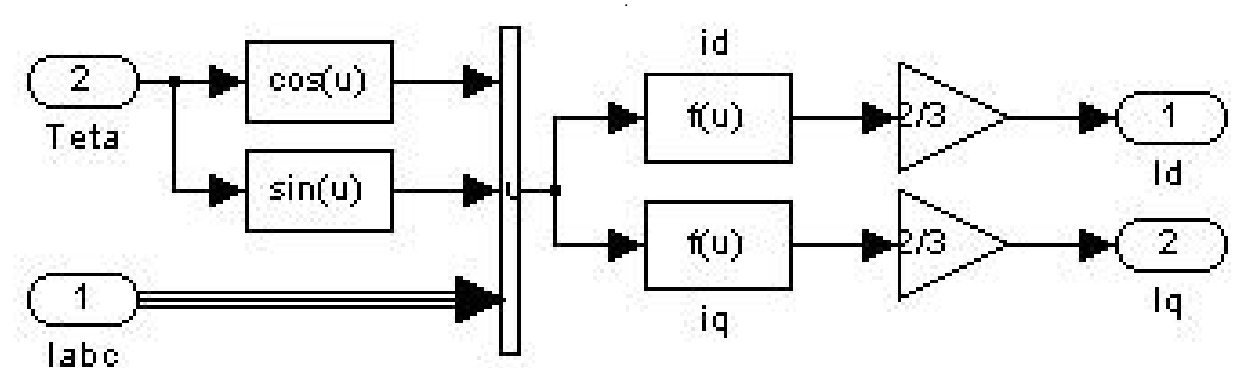

Рис. 1. Развернутая блок схема прямого координатного преобразования.

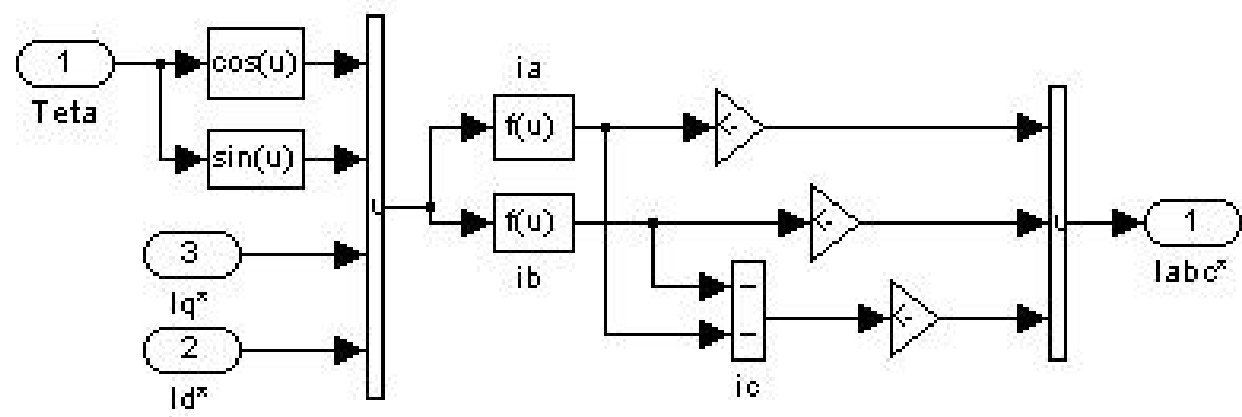

Рис. 2. Развернутая блок схема обратного координатного преобразования.

прямого управления моментом. Для создания такого управления необходимо поддерживать ортогональность статорного тока и потока ротора при вращающемся роторе.

Для моделирования подобной системы управления понадобятся следующие блоки: блоки прямого и обратного координатного преобразования; блоки вычислителей токов id (для создания потока ротора) и iq (для создания потока намагничивания); вычислителя угла $\theta$ (угол между током ротора и потоком намагничивания); вычислителя фактического магнитного потока ротора, в цепях обратной связи; модулятора тока (для формирования ШИМ); инвертора (блок формирования ШИМ); ПИ регулятора (блока формирования закона регулирования момента или частоты вращения ротора). Рассмотрим вышеперечисленные блоки.

Развернутая структура блока прямого координатного преобразования представлена на рисунке 1.

Данная блок схема преобразует мгновенные значения токов из неподвижной системы координат статора $I_{C}, I_{B}, I_{B}$. в подвижную систему координат ротора id и iq. Преобразование выполняется по формулам координатных преобразований из двухфазной системы в трёхфазную (см. формулу (1), а также из неподвижной системы координат в подвижную по прямому преобразованию Парка (см. формулу (2)):

$$
\begin{gathered}
\left\{\begin{array}{c}
I_{a}=I_{A} \\
I_{b}=\frac{I_{B}-I_{C}}{\sqrt{3}}
\end{array}\right. \\
\left\{\begin{array}{l}
i_{q}=I_{b} \sin \varphi+I_{a} \cos \varphi \\
i_{d}=I_{b} \cos \varphi+I_{a} \sin \varphi
\end{array}\right.
\end{gathered}
$$

Выражение в блоке Id:

$u[1]^{*} u[3]+\left(1.7320508^{*} u[2]-u[1]\right)^{*} u[4]^{*} 0.5+(-u[1]-$ $\left.1.7320508^{*} u[2]\right)^{*} u[5]^{*} 0.5$.

Выражение в блоке lq:

$-u[2]^{*} u[3]+\left(u[2]+1.7320508^{*} u[1]\right)^{*} u[4]^{*} 0.5+(u[2]-$ $\left.1.7320508^{*} u[1]\right)^{*} u[5]^{*} 0.5$.

Развернутая структура блока обратного координатного преобразования представлена на рисунке 2.

Данная блок схема преобразует токи из подвижной системы координат ротора id и iq в неподвижную систему координат статора: $I_{C}, I_{B}, I_{B}$.

Преобразование выполняется по формулам координатных преобразований из подвижной системы координат в неподвижную по обратному преобразованию Парка (см. формулу (3), а также из двухфазной системы в трёхфазную (см. формулу (4): 


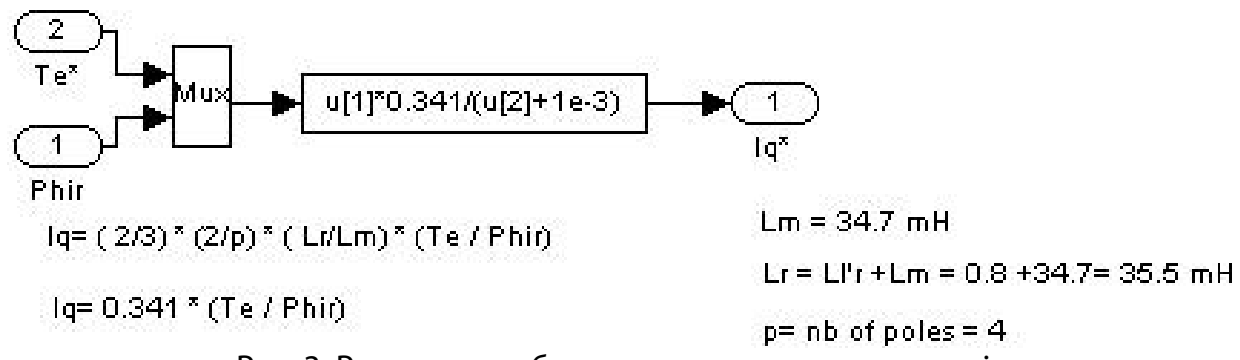

Рис. 3. Развернутая блок схема вычислителя тока iq.

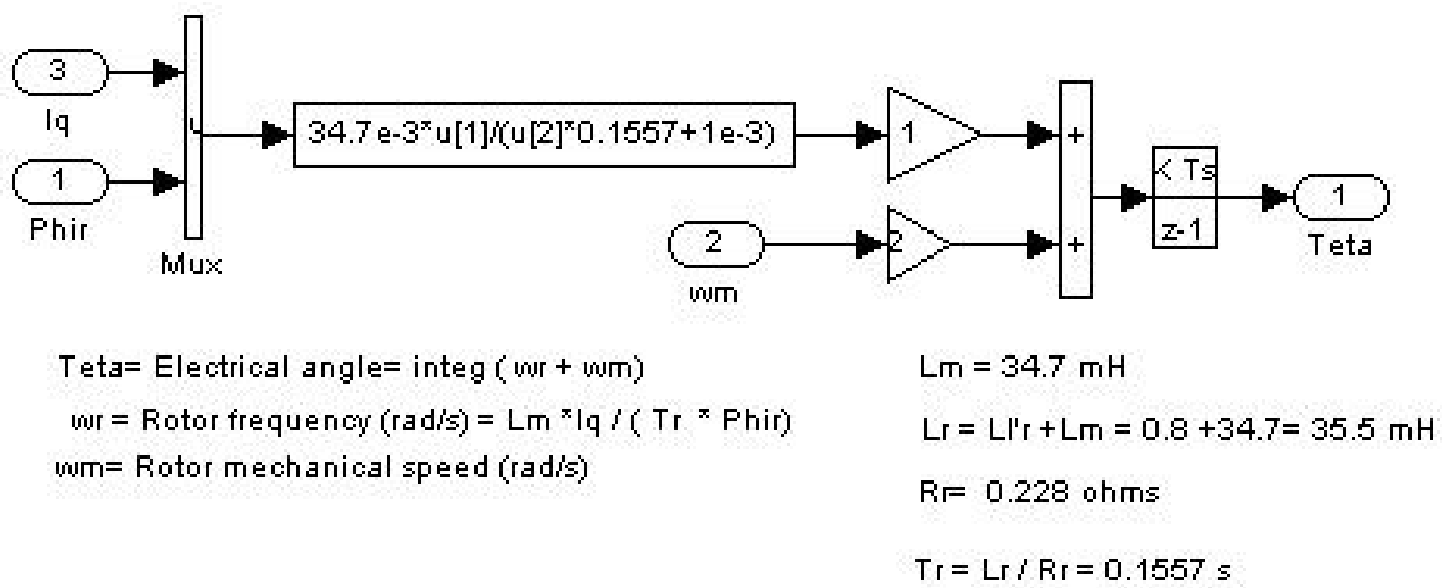

Рис. 4. Развернутая блок схема вычислителя угла $\theta$.

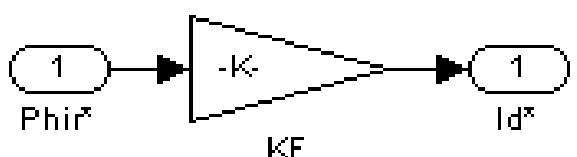

$$
\begin{aligned}
& \text { Id }^{x}=\mathrm{Phir}^{x} / \mathrm{Lm} \\
& \mathrm{Lm}=34.7 \mathrm{mH}
\end{aligned}
$$

Рис. 5. Развернутая блок схема вычислителя тока id.

$\left\{\begin{array}{l}I_{a}=i_{q} \cos \varphi+i_{d} \sin \varphi \\ I_{b}=i_{q} \sin \varphi+i_{d} \cos \varphi\end{array}\right.$

$$
\left\{\begin{array}{c}
I_{A}=I_{a} \\
I_{B}=\frac{\sqrt{3}}{2} I_{b}-\frac{1}{2} I_{a} \\
I_{C}=-\frac{1}{2} I_{a}-\frac{\sqrt{3}}{2} I_{b}
\end{array}\right.
$$

Выражение в блоке la:-u[3]* $u[2]+u[4]^{*} u[1]$.

Выражение в блоке lb: $\left(u[1]+1.7320508^{*} u[2]\right)^{*} u[4]^{*} 0.5+$ $\left(u[2]+1.7320508^{*} u[1]\right)^{*} u[3]^{*} 0.5$

Развернутая структура вычислителя тока іq представлена на рисунке 3.
В этом блоке реализуется основное уравнение момента двигателя ориентированное по потокосцеплению ротора. Данный закон описывается формулой (5):

$$
i_{q}=\frac{2}{3} \times \frac{2}{\mathrm{P}} \times \frac{L_{r}}{L_{m}} \times \frac{M}{\mathrm{w}_{r}}(5)
$$$$
\text { где } L_{r}=L_{m}+L_{\mathrm{y} r} \text { - индуктивность цепи ротора }
$$
(для данной модели составляет 35.5 мГн), $L_{m}$ - индуктивность намагничивания (34.7мГн задается с параметрами двигателя), $L_{\mathrm{yr}}-$ индуктивность рассеивания (0.8 мГн задается с параметрами двигателя), Р - полюсность статора (для данной модели $\mathrm{P}=4$ ).

Выполняемое выражение в математическом блоке приобретает вид: u[1]*0.341/(u[2]+1e-3). 

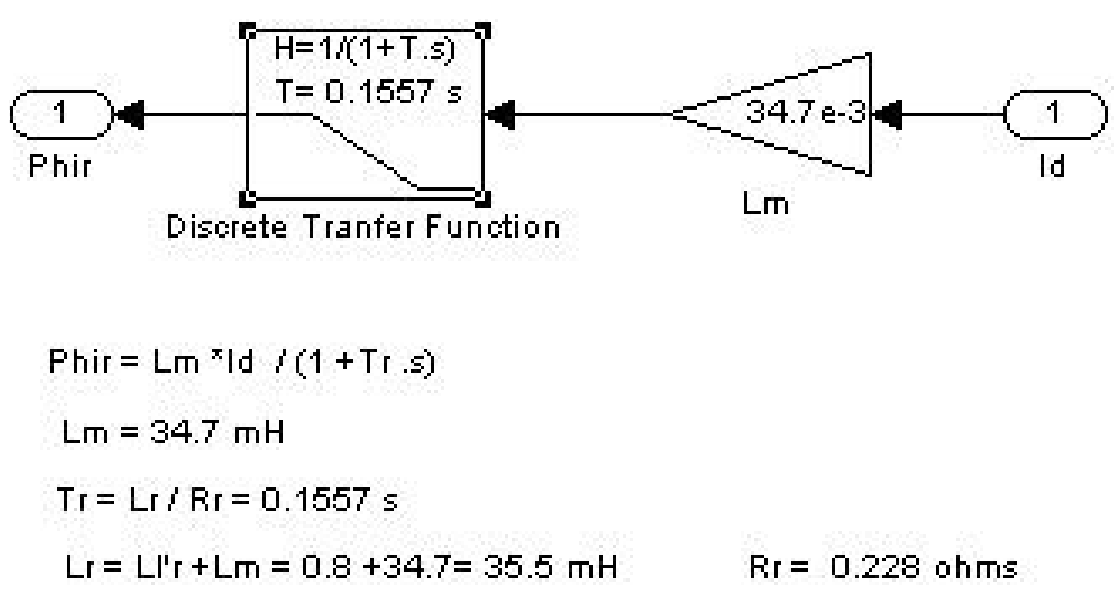

Рис. 6. Развернутая блок схема вычислителя потокосцепления ротора $\psi r$.

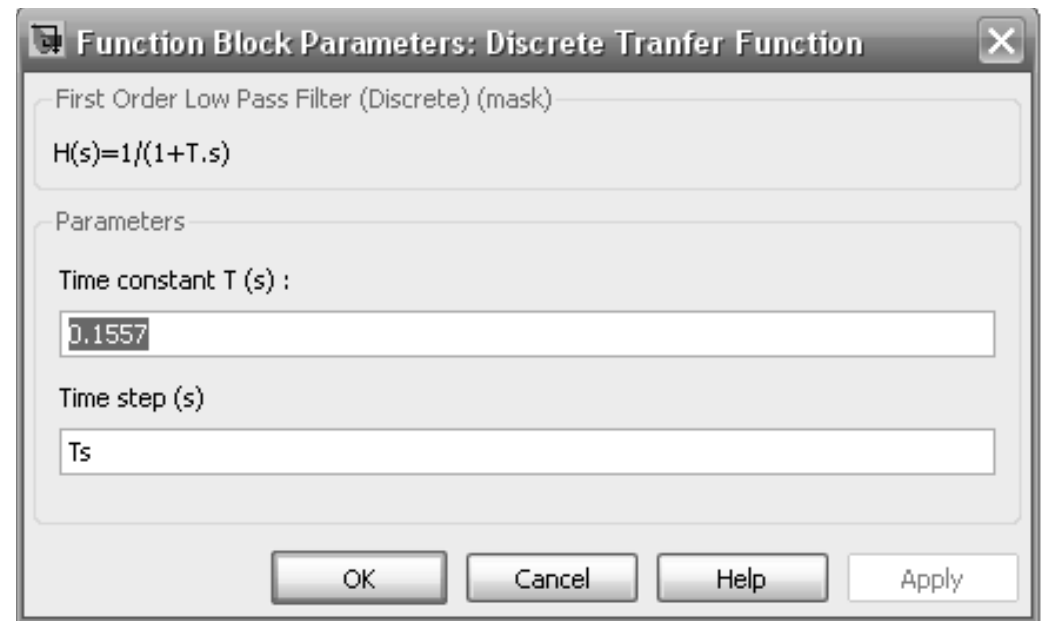

Рис. 7. Окно настроек дискретной передаточной функции.

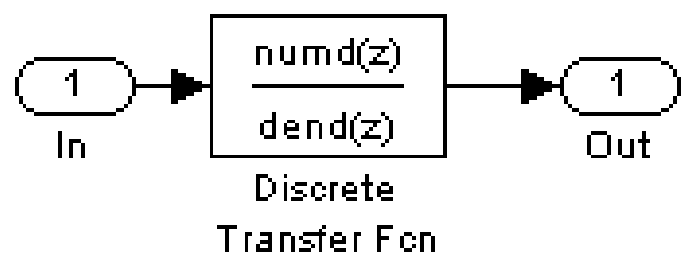

Рис. 8. Развернутая структура дискретной передаточной функции.

Развернутая блок схема вычислителя угла $\theta$ представлена на рисунке 4. Вычислитель угла предназначен для вычисления текущего угла между током в роторе $I_{R}$ : и магнитным потоком со стороны статора $ш_{m}$.

В данном блоке производится интегрирование суммы частот вращения ротора $щ_{r}$ и частоты тока в роторе щ $_{i r}$ :

$$
\text { и }=\int\left(щ_{r}+щ_{i r}\right) d t
$$

Частота тока в роторе небольшая значительно меньше частоты тока в статоре и определяется она выражением:

$$
щ_{i r}=\frac{L_{m} \times i q}{M \times T_{r}}
$$

$$
\text { где } T_{r}=\frac{L_{r}}{R_{r}}-
$$

постоянная времени ротора, $R_{r}$ - активное сопротивление ротора (для данной модели $R_{r}=0.0228$ Ом). При 


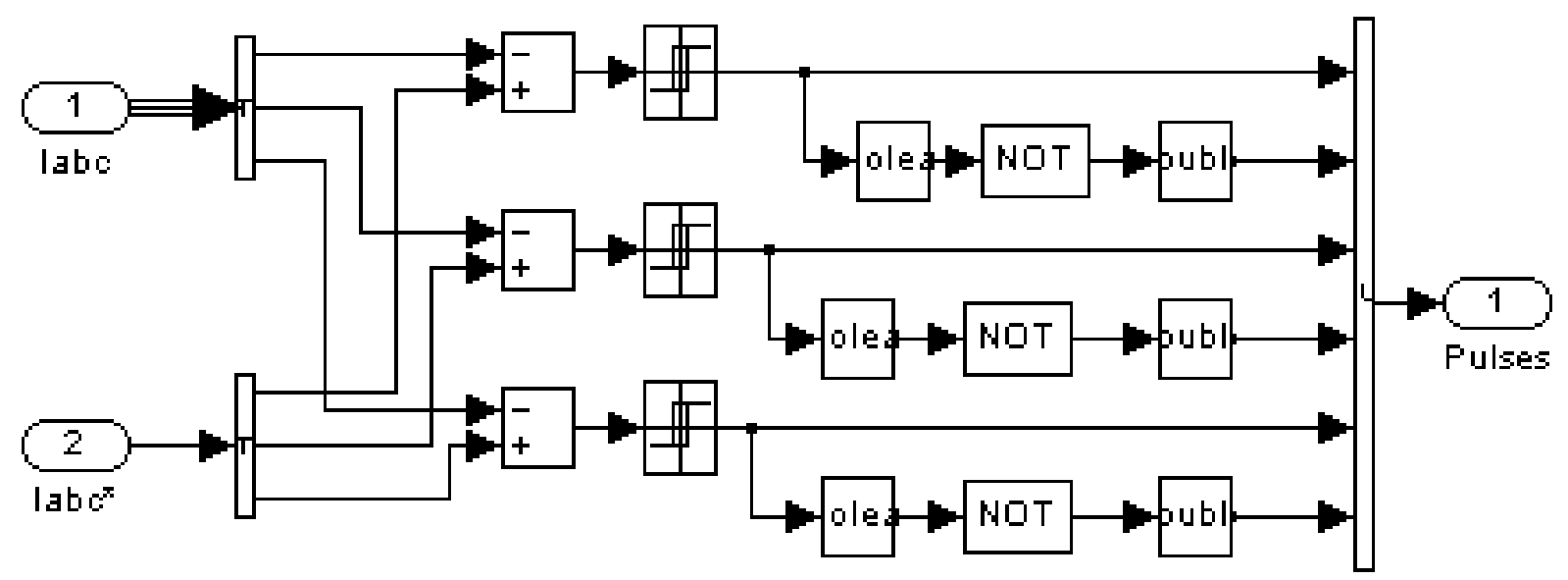

Рис. 9. Развернутая блок схема регулятора тока.

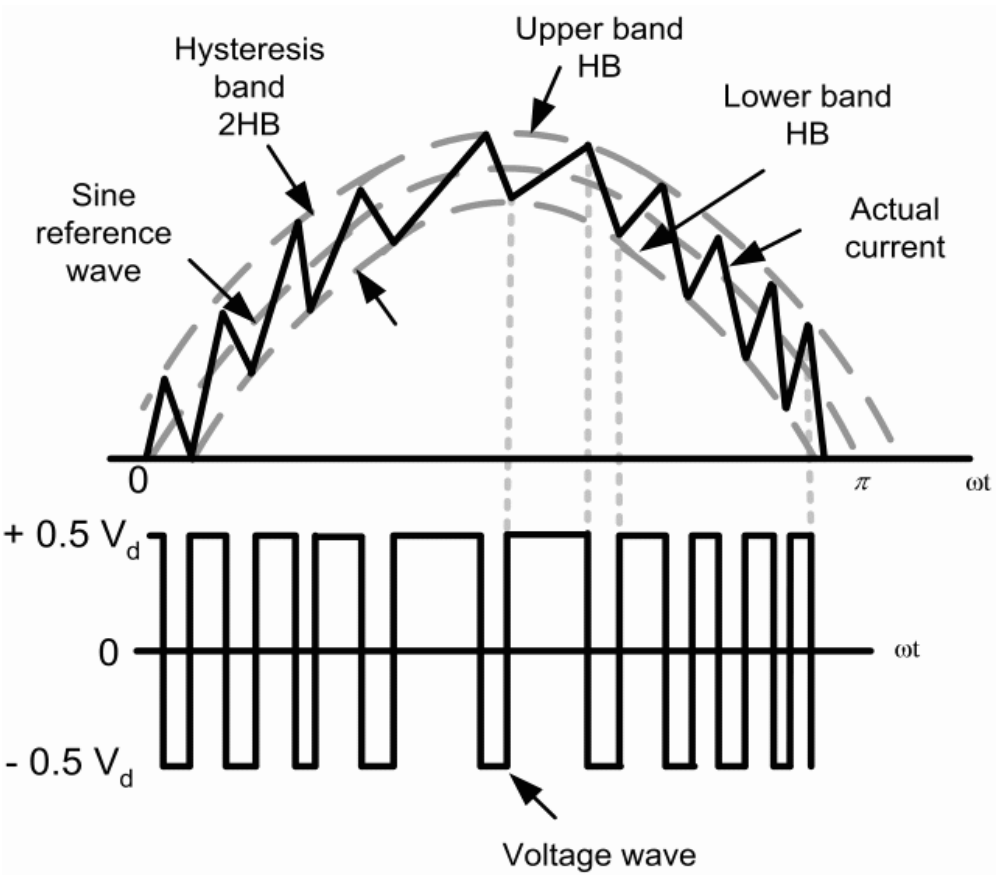

Рис. 10. Работа гистерезисного регулятора тока.

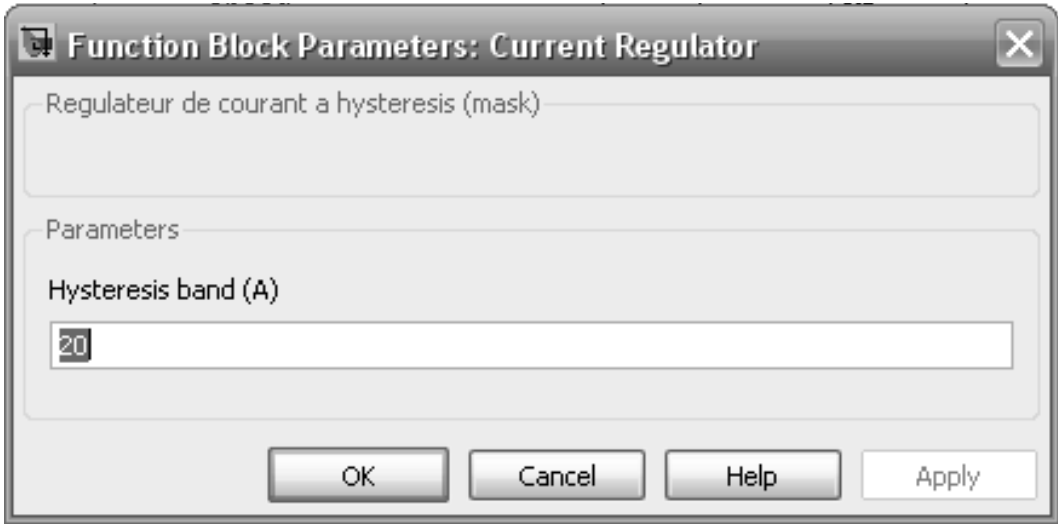

Рис. 11. Установка значения гистерезиса в окне настроек. 


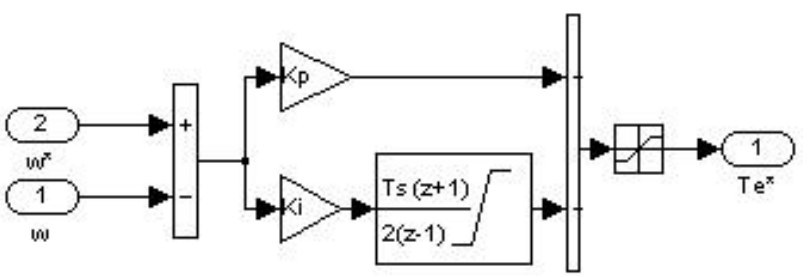

Рис. 12. Развернутая блок схема ПИ регулятора.

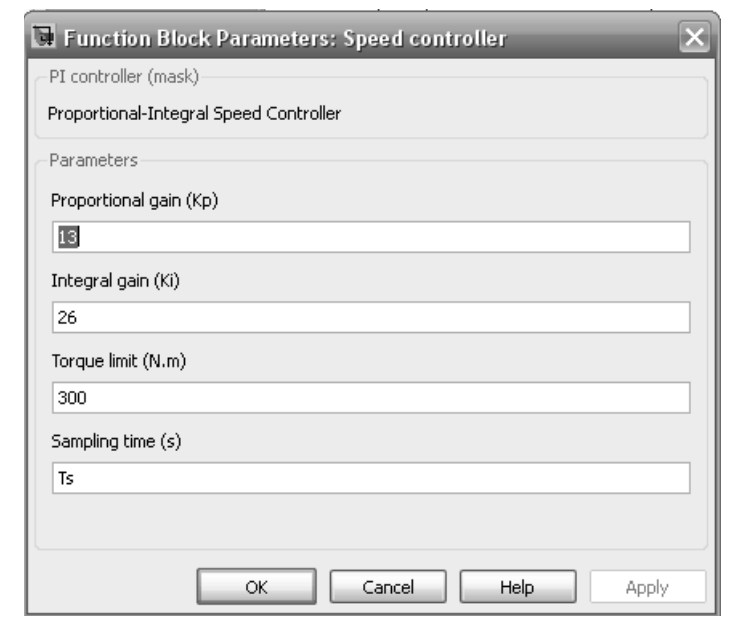

Рис. 13. Установка значения в окне настроек ПИ-регулятора.

заданных параметрах двигателя выражение в математическом блоке для вычисления частоты тока в роторе будет принимать значение: $34.7 \mathrm{e}-3^{*} \mathrm{u}[1] /\left(\mathrm{u}[2]^{*} 0.1557+1 \mathrm{e}-3\right)$.

Структура вычислителя тока id представлена на рисунке 5.

Вычислитель тока id предназначен для формирования фиксированного потокосцепления ротора. Это потокосцепление задается на входе этого блока. Далее в нем вычисляется ток id как отношение потокосцепление ротора к индуктивности намагничивания.

$$
\mathrm{id}=ш_{r} / L_{m}
$$

Выполняемое выражение в блоке умножения: 1/34.7e-3.

Развернутая блок схема вычислителя потокосцепления ротора $\psi_{r}$ представлена на рисунке 6.

Для вычисления потокосцепления ротора необходимо знать: $T_{r}$ - постоянную времени ротора, $L_{m}-$ индуктивность намагничивания и величину тока id. Вычисления производятся по следующей формуле:

$$
\psi_{\mathrm{r}}=L_{\mathrm{m}} \times \mathrm{id} \times \frac{1}{1+T_{r s}}
$$

где $\frac{1}{1+T_{r s}}-$

z преобразованная передаточная функция, основным параметром которой является постоянная времени $T_{r}$. Постоянную времени ротора указывают в окне параметров этой функции, рисунок 7

Развернутая структура дискретной передаточной функции представлена на рисунке 8

Развернутая блок схема модулятора тока представлена на рисунке 9.

Данный блок поддерживает ток в обмотках статора в пределах зоны гистерезиса. В этом блоке происходит сравнение токов фактических с токами опорными для получения сигналов управления инвертором при формировании ШИМ. Работу этого блока поясняет рисунок 10.

Основным параметром регулятора тока является установка гистерезиса в окне настроек рисунок 11.

Развернутая структура пропорционально-интегрального регулятора представлена на рисунке 12.

Пропорционально-интегральный регулятор (ПИ-регулятор) предназначен для поддержания постоянной 


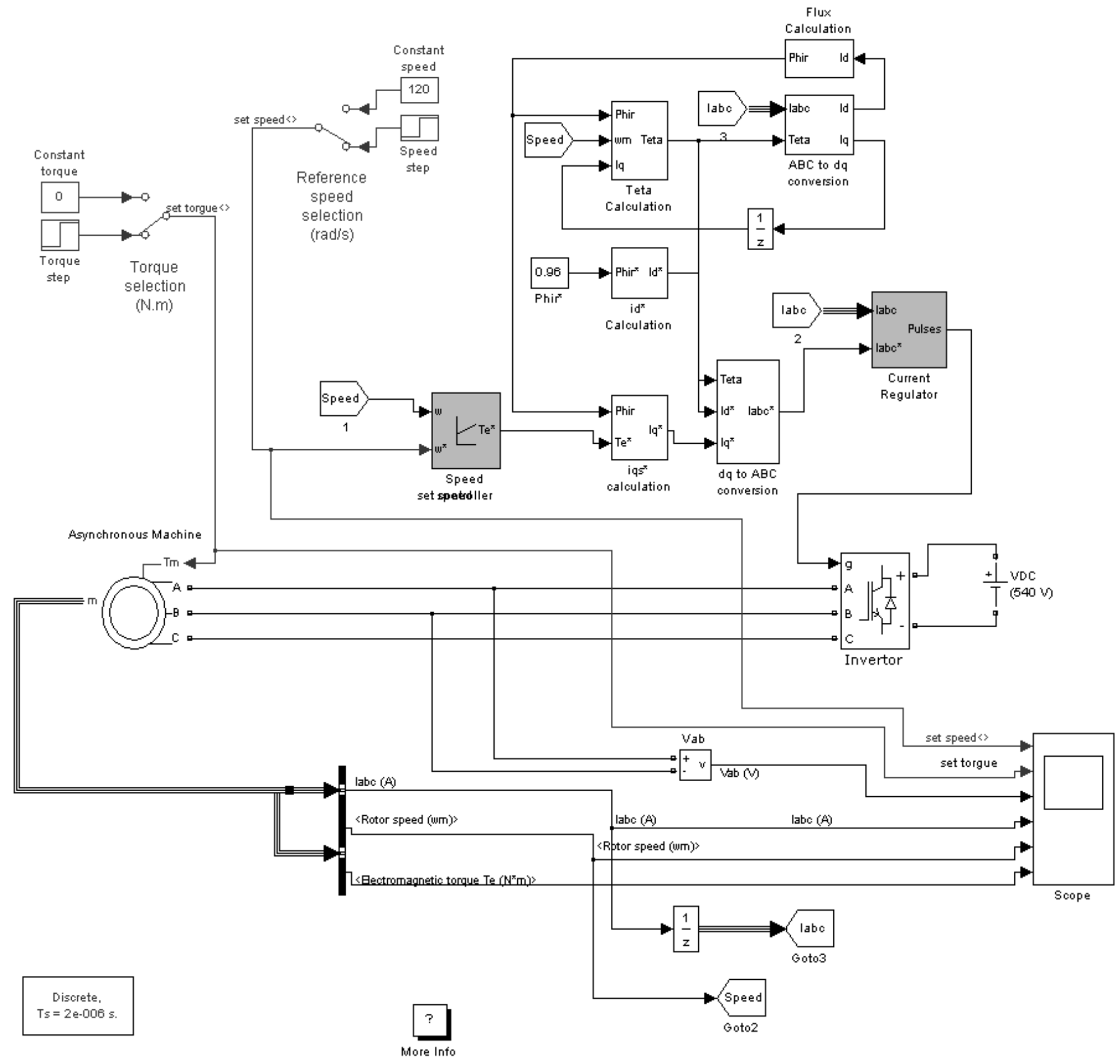

Рис. 14. Блок схема модели векторного управления.

скорости вращения ротора двигателя. Для корректной работы ПИ-регулятора необходимо задать пропорциональные и интегральные коэффициенты, а также предел регулируемой величины (предел крутящего момента). На рисунке 13 представлено окно настроек ПИ-регулятора, где вводятся указанные выше значения.

По окончании формирования блоков подсистем и сборки модели выполняются необходимые настройки. На рисунке 14 представлена блок схема готовой настроенной модели, выполненной из вышеописанных блоков.
При запуске моделирования зададим, постоянное потокосцепление ротора в виде константы на входе модели, ступенчато зададим изменение частоты вращения ротора и момента. На рисунке 15 приводятся результаты моделирования.

Моделирование проводим на интервале в 3 секунды. На первой секунде двигатель разгоняется до установившегося значения в 50 рад/сек, к концу второй секунды ротор разгоняется до 160 рад/сек. Со второй секунды увеличивается момент сопротивления на валу двигате- 


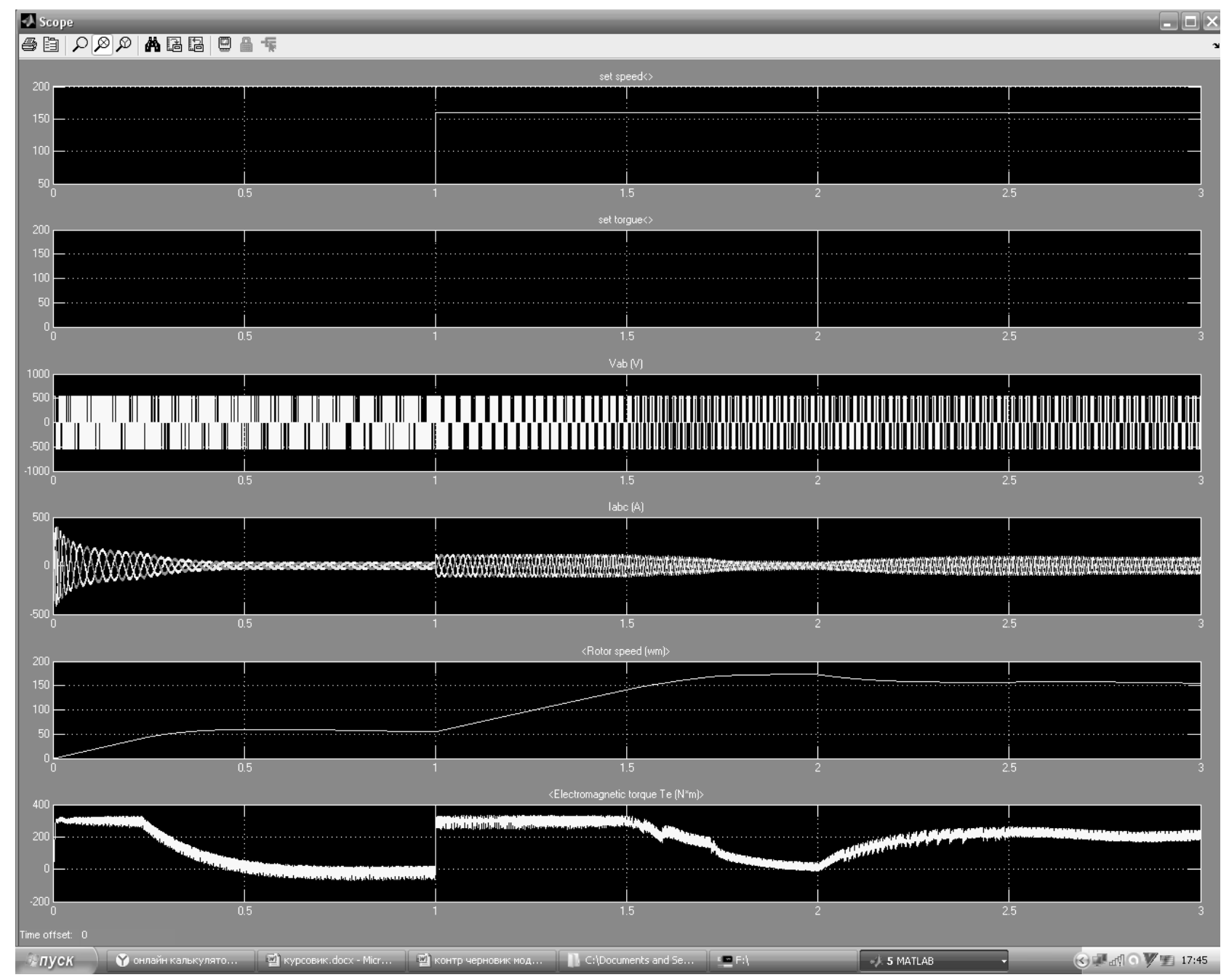

Рис. 15. Результат моделирования настроенной модели.

ля от нуля до 200 Нм и как видно из диаграмм электромеханический момент двигателя обеспечивает момент нагрузки. При этом из диаграмм видно, как фазные токи увеличены при увеличении момента или при разгоне двигателя.

\section{ВывОАы}

Раскрытая в данной работе структура векторного управления асинхронным короткозамкнутым двигате- лем носит познавательный характер, расширяет возможность исследования систем данного типа. На сегодняшний день хоть векторное управление и не является не изученным, однако в процессе моделирования в системе MATLAB могут возникать вопросы. Поэтому материал данной статьи был нацелен на разрушение сложности моделирования векторного управления в пакете расширения Simulink. Исследования созданной модели показали её полную работоспособность и хорошие показатели управляемости двигателя в динамике.

\section{ЛИТЕРАТУРА}

1. Калачёв Ю. Н. Векторное регулирование (заметки и практика). 2013 г. Издательство компании «ЭФ0» [Электронный pecypc]. URL: http://www.efo-power. ru (дата обращения 12.10.2020).

2. «Хабр» [Электронный ресурс]. URL: https://habr.com (дата обращения 12.10.2020).

3. «Векторное управление асинхронными двигателями». Учебное пособие по дисциплинам электромеханического цикла. Санкт-Петербург. 2002. [Электронный ресурc]. URL: https://pandia.ru (дата обращения 12.10.2020). 
4. «НПФ Вектор» [Электронный ресурc]. URL: http://motorcontrol.ru (дата обращения 12.10.2020).

5. Ресурсы MATLAB7.7.0 (R2008b).

6. Национальный исследовательский университет «Информационных Технологий Механики и Оптики». Кафедра: «Электротехники и прецизионных электромеханических систем». [Электронный ресурc]. URL: http://ets.ifmo.ru (дата обращения 12.10.2020).

7. Образовательный портал Пензенского Государственного Технического Университета. «Алгоритм расчёта параметров схемы замещения асинхронного двигателя по каталожным данным». [Электронный ресурc]. URL: http://edu.tltsu.ru (дата обращения 12.10.2020).

8. В. Н. Абабурко; А. В. Шваяков «Векторное управление электродвигателями переменного тока». Учебное издание. Часть 1. Издательство ГУ ВПо Белорусско-Российского университета. 2013. [Электронный ресурc]. URL: http://e.biblio.bru.by (дата обращения 12.10.2020).

9. Технический каталог. Изд. РУСЭЛПРОМ. 2008. [Электронный ресурc]. URL: http://vecgroup.com (дата обращения 12.10.2020).

10. Мощинский Ю. А., Беспалов В.Я., Кирякин А. А. «Определение параметров схемы замещения асинхронной машины по каталожным данным» // «Электричество».— № 4.- С. 38-42.

(c) Русаков Максим Геннадьевич ( е10е00@mail.ru ),

Евдокимов Александр Сергеевич (evd15@list.ru), Занкин Александр Иванович (zankin_ai@mail.ru).

Журнал «Современная наука: актуальные проблемы теории и практики»

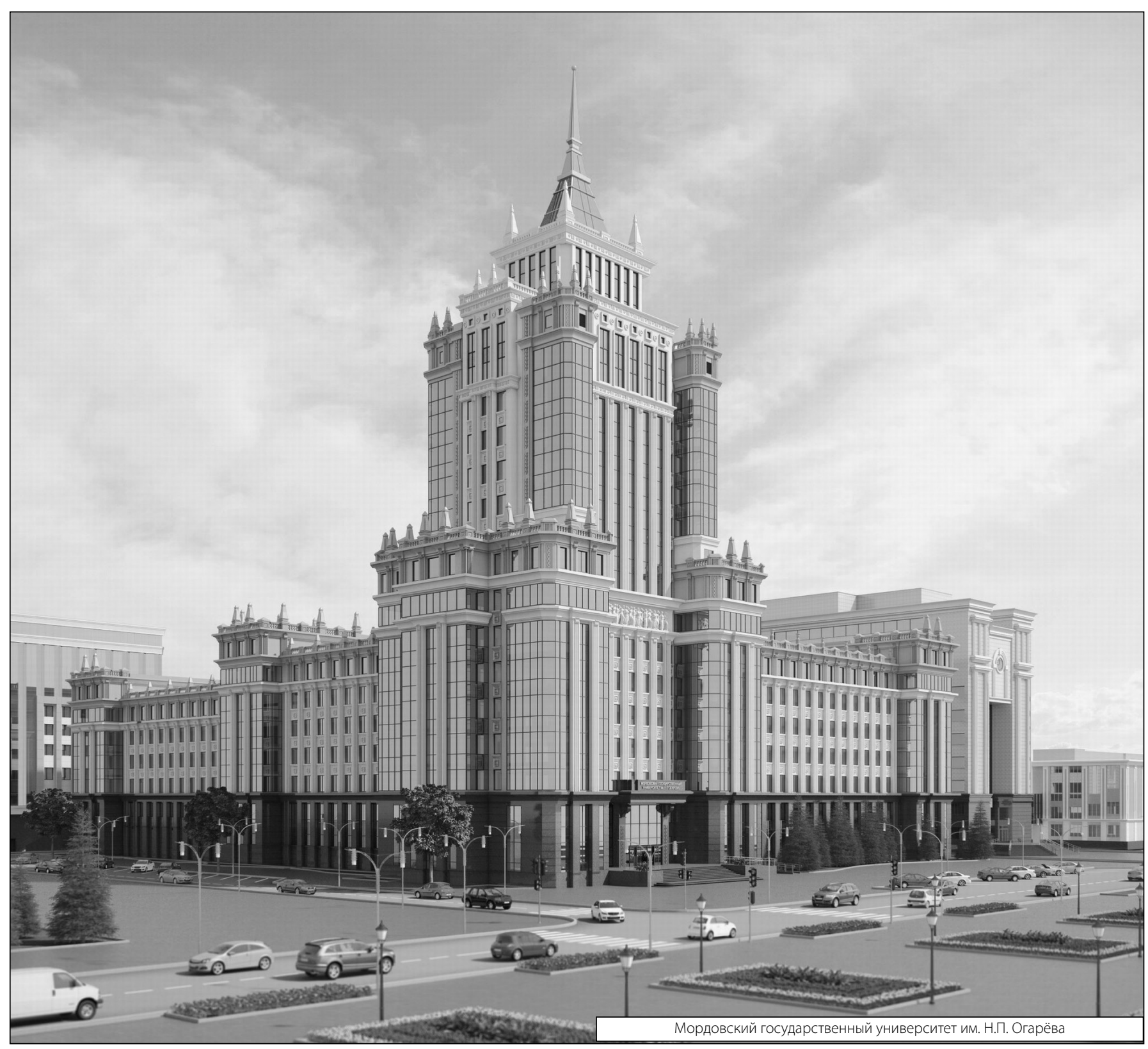

